\title{
S100A8/A9 in Myocardial Infarction: A Promising Biomarker and Therapeutic Target
}

\author{
ZhuLan Cai 1,2, Qingwen Xie ${ }^{1,2}$, Tongtong Hut,2, Qi Yao', Jinhua Zhao',2, Qingqing Wu ${ }^{1,2 *}$ \\ and Qizhu Tang ${ }^{1,2 *}$ \\ ${ }^{1}$ Department of Cardiology, Renmin Hospital of Wuhan University, Wuhan, China, ${ }^{2}$ Hubei Key Laboratory of Metabolic \\ and Chronic Diseases, Wuhan, China
}

OPEN ACCESS

Edited by:

Cheng Yang,

Fudan University, China

Reviewed by:

Alexandru Schiopu,

Lund University, Sweden

Peifeng $L i$,

Qingdao University, China Kun Wang,

Qingdao University, China

Thomas Vogl,

Universitätsklinikum Münster

Germany

*Correspondence: Qizhu Tang

qztang@whu.edu.cn

Qingqing Wu

qingwu20130@whu.edu.cn

Specialty section:

This article was submitted to

Molecular Medicine,

a section of the journal

Frontiers in Cell and Developmental

Biology

Received: 08 September 2020

Accepted: 21 October 2020

Published: 12 November 2020

Citation:

Cai Z, Xie Q, Hu T, Yao Q, Zhao J, Wu $Q$ and Tang Q (2020) S100A8/A9 in Myocardial Infarction: A Promising

Biomarker and Therapeutic Target. Front. Cell Dev. Biol. 8:603902. doi: 10.3389/fcell.2020.603902
Myocardial infarction (MI), the main cause of cardiovascular-related deaths worldwide, has long been a hot topic because of its threat to public health. S100A8/A9 has recently attracted an increasing amount of interest as a crucial alarmin that regulates the pathogenesis of cardiovascular disease after its release from myeloid cells. However, the role of S100A8/A9 in the etiology of $\mathrm{Ml}$ is not well understood. Here, we elaborate on the critical roles and potential mechanisms of S100A8/A9 driving the pathogenesis of Ml. First, cellular source of S100A8/A9 in infarcted heart is discussed. Then we highlight the effect of S100A8/A9 heterodimer in the early inflammatory period and the late reparative period of $\mathrm{Ml}$ as well as myocardial ischemia/reperfusion (I/R) injury. Moreover, the predictive value of S100A8/A9 for the risk of recurrence of cardiovascular events is elucidated. Therefore, this review focuses on the molecular mechanisms of S100A8/A9 in $\mathrm{Ml}$ pathogenesis to provide a promising biomarker and therapeutic target for $\mathrm{Ml}$.

Keywords: S100A8/A9, cardiovascular diseases, myocardial infarction, ischemia/reperfusion, biomarker, therapeutic target

\section{INTRODUCTION}

Myocardial infarction (MI), a universal public health issue with high mortality and morbidity rates worldwide, seriously threatens the lives and health of people and contributes to expensive medical expenditures (Reed et al., 2017). Acute MI (AMI) is identified as myocardial necrosis that begins with acute and persistent coronary ischemia and hypoxia (Heusch and Gersh, 2017). AMI mostly occurs in the context of coronary atherosclerosis, and it manifests when the coronary atherosclerotic plaque ruptures due to changes in physiological and hemodynamic factors, such as high local wall stress and low endothelial shear stress (Ahmadi et al., 2019). Platelets and other components accumulate on the surface of the ruptured plaque, causing thrombosis. Once a developing thrombus completely or partially obstructs the coronary artery, the blood and energy supply to the heart becomes restricted. The pathogenesis of MI involves mitochondrial calcium overload, increase in hydrogen ion concentration, cellular ATP depletion, dysregulation of inflammatory cytokines, and oxidative stress (Kalogeris et al., 2016). Therefore, in the process of exploring the pathophysiological and molecular mechanism of MI, identifying new markers for early diagnosis of MI, evaluating the prognosis, and guiding new therapeutic strategies have become current research hotspots.

There is growing experimental and clinical evidence that the S100 protein family has been implicated in the occurrence and development of multiple cardiovascular diseases, and these 
proteins are expected to become new targets for prevention (Gonzalez et al., 2020). For example, serum S100A levels increase after acute ischemic events, are highly sensitive in myocardial injury, and may be a candidate biomarker for the diagnosis of AMI (Aydin et al., 2019). At present, a growing body of evidence has illustrated that S100A8 and its heterodimeric partner S100A9 in the S100 family are expected to not only be biomarkers to evaluate the prognosis of patients with MI (Morrow et al., 2008) but also provide new ideas for patient treatment, opening a novel field of MI research. Based on accumulating experimental evidence, S100A8/A9 also functions as an important regulator of other cardiovascular disorders, such as hypertension (Wu et al., 2014), viral myocarditis (Muller et al., 2017), autoimmune myocarditis (Otsuka et al., 2009; Muller et al., 2020), doxorubicin-induced cardiotoxicity (Pei et al., 2016), cardiac hypertrophy (Wei et al., 2015), and sepsis-associated cardiomyopathy (Boyd et al., 2008).

In the present review, we focus on relevant experimental and clinical studies concerning the roles and mechanisms by which S100A8/A9 affects the pathophysiology of MI to provide valid evidence for clinical applications in the future.

\section{S100A8 AND S100A9 PROTEINS: IMPORTANT MEMBERS OF THE $\$ 100$ PROTEIN FAMILY}

\section{The S100 Protein Family}

The S100 proteins were named because of their ability to dissolve in $100 \%$ neutral saturated ammonium sulfate solution and belong to a unique class of non-ubiquitous small molecular weight (10-12 kDa) (Bresnick et al., 2015), $\mathrm{Ca}^{2+}$-modulated proteins, which were first identified in nervous system by Moore (1965). The S100 family currently has 25 known different members (including S100A1-16, S100G, S100P, and S100B), which are highly similar in sequence and structure (Gonzalez et al., 2020), and they all contain calcium-binding protein motifs (Bresnick et al., 2015). Schafer and Heizmann (1996) reported that S100 proteins consist of two distinct helix-loop-helix elongation factor (EF) hands flanked by conserved hydrophobic regions at the $\mathrm{C}$ - and N-terminal and connected by a central hinge region. The N-terminus usually forms a loop structure composed of 14 amino acids and has a low affinity for $\mathrm{Ca}^{2+}$, while the C-terminus is defined as the typical $\mathrm{Ca}^{2+}$-binding loop, which contains 12 amino acids and has a high affinity for $\mathrm{Ca}^{2+}$ (Schafer and Heizmann, 1996). S100 proteins undergo pronounced conformational changes upon binding of $\mathrm{Ca}^{2+}$ to the EF-hand, exposing a hydrophobic patch and facilitating discrimination of a variety of different target receptors and proteins (Donato, 2003; Santamaria-Kisiel et al., 2006).

The S100 family of proteins is encoded by their respective genes, which are highly conserved among different species (Marenholz et al., 2004). Despite the fact that S100 proteins are only expressed in vertebrates, each protein exhibits a unique pattern of tissue-specific and cell-specific expression. Furthermore, the expression of $\mathrm{S} 100$ proteins is strictly orchestrated for the purpose of ensuring the maintenance of immune homeostasis (Donato, 2003; Zimmer et al., 2013).

Unlike calmodulin, a kind of $\mathrm{Ca}^{2+}$-binding protein, which only exerts intracellular effects to regulate biological activity, some S100 proteins serve both as extracellular signaling proteins and intracellular mediators, thereby participating in multiple intracellular and/or extracellular regulatory processes in either an autocrine or paracrine manner (Donato, 2001; Donato et al., 2013). It has been reported that several extracellular S100 proteins function as damage-associated molecular patterns (DAMPs) by binding to a series of membrane receptors, such as Toll-like receptor-4 (TLR-4), receptor for advanced glycation end products (RAGE), and G-protein coupled receptors (Goyette and Geczy, 2011; Pruenster et al., 2016), participating in the control of diverse physiological functions, including proliferation, differentiation, migration/invasion, inflammation, oxidative stress, $\mathrm{Ca}^{2+}$ homeostasis, cell apoptosis, glycogen phosphorylation, and aggregation of macrophages (Donato et al., 2013).

\section{Expression and Structural Characteristics of S100A8/A9}

S100A8 and S100A9 proteins are important members of the S100 family and are also named myeloid-related protein 8 (MRP8) and MRP14, respectively, due to their abundance in cells of myeloid origin (Odink et al., 1987). These proteins have unique expression profiles in different types of cells; for example, these proteins are present in some innate immune cells, including dendritic cells, neutrophils, and monocytes (Averill et al., 2011). S100A8 and S100A9 constitute approximately 40\% of neutrophil cytosolic proteins and approximately $1 \%$ of monocyte cytosolic proteins (Hessian et al., 1993). However, upon activation under certain conditions, expression of these proteins is also induced in fibroblasts (Rahimi et al., 2005), mature macrophages (Ingersoll et al., 2010), vascular endothelial cells (McCormick et al., 2005; Yao and Brownlee, 2010; Landers-Ramos et al., 2017), vascular smooth muscle cells (Inaba et al., 2009), keratinocytes (Grimbaldeston et al., 2003), epithelial cells, and osteoclasts (Ehrchen et al., 2009).

The S100A8 and S100A9 genes, along with many other S100 protein genes, are located on chromosome 1q21 and form the S100 gene cluster, which is a hot spot for chromosome changes (Lesniak, 2011). It has been reported that the deletion or mutation of chromosomes in this region is closely related to the occurrence of cancer (Bresnick et al., 2015). The human S100A8 gene encodes a small molecule protein composed of 93 amino acids with a molecular mass of $10.8 \mathrm{kDa}$, while the human S100A9 gene encodes a protein consisting of 113 amino acids with a molecular mass of $13.2 \mathrm{kDa}$ (Zou et al., 2013; Wang et al., 2018). S100A8 and S100A9 exist in several forms and can be homodimers, heterodimers, and tetramers (Leukert et al., 2005, 2006; Schiopu and Cotoi, 2013). Due to the poor stability of homodimers, these proteins preferentially form S100A8/A9 heterodimer complexes, which are the most dominant forms of these proteins under physiological conditions (Donato et al., 2013). 
Additionally, S100A9 exerts a significant effect in maintaining the stability of the S100A8 protein (Hobbs et al., 2003; Manitz et al., 2003). S100A8 and S100A9 form non-covalently linked polymers (S100A8/A9), also known as calprotectin, which have been demonstrated to possess pleotropic biological properties (Vogl et al., 2006). When $\mathrm{Ca}^{2+}$ is at an appropriate concentration, S100A8/A9 heterodimers polymerize to form $(\mathrm{S} 100 \mathrm{~A} 8 / \mathrm{A} 9)_{2}$ tetramers that are essential for biological activities (Leukert et al., 2006).

\section{Biological Functions of S100A8/A9}

Targeted deletion of the S100A8 gene in mice is lethal (Passey et al., 1999), suggesting the significance of S100A8 in early embryonic development, while mice that are genetically deficient in S100A9 have a generally healthy phenotype but do not express S100A8 proteins (Hobbs et al., 2003; Manitz et al., 2003). Consequently, it is accepted that S100A9-knockout (KO) mice are available as functional S100A8 and S100A9 doubleKO mice.

Intracellular S100A8/A9 has been considered to potentiate NADPH oxidase activity by interacting with $\mathrm{p} 47$ phox and p67phox, two important cytosolic factors of the NADPH complex (Doussiere et al., 2001, 2002). Moreover, the formation of (S100A8/A9) 2 tetramers in a calcium-dependent manner promotes tubulin polymerization and microtubule formation (Leukert et al., 2006). The reorganization of the microtubules, which is a prerequisite for the successful transendothelial migration of phagocytes, is regulated by S100A9 phosphorylation via the p38 mitogen-activated protein kinase (MAPK) signaling pathway (Vogl et al., 2004). Accordingly, intracellular S100A8/A9 acts a pivotal part in regulating the migration of phagocytes.

S100A8/A9 is also actively secreted or passively released from specific cells. It is specifically released by activated phagocytes in the context of inflammation during the interaction between phagocytes and activated endothelial cells (Frosch et al., 2000; Pruenster et al., 2015). The secretion of S100A8/A9 lacks signal peptides that are essential for the classic endoplasmic reticulum/Golgi pathway (Rammes et al., 1997) but seems to depend on reactive oxygen species (ROS) and $\mathrm{K}+$ exchanges through ATP-sensitive $\mathrm{K}(+)$ channels (Tardif et al., 2015). In contrast, passive release is usually an outcome of neutrophil death (Voganatsi et al., 2001), either by necrosis or NETosis (Urban et al., 2009), which requires the production of ROS by NADPH oxidase (Fuchs et al., 2007). Innate immune cells, such as neutrophils and monocytes, express PRRs on their surface, which bind to pathogen-associated molecular patterns (PAMPs) or damage-associated molecular patterns (DAMPs) under diverse pathological conditions, inducing intracellular activation of numerous signal cascades (Newton and Dixit, 2012). Extracellular S100A8/A9 functions as a DAMP to activate RAGE (Ehlermann et al., 2006; Boyd et al., 2008) and TLR-4 (Vogl et al., 2007; Ehrchen et al., 2009), thereby acting as a potent stimulator of the innate immune response in a diversity of diseases.

Extracellular S100A8/A9 is an active mediator of various inflammatory conditions. Monocytes and macrophages treated with S100A8/A9 are able to secrete inflammatory cytokines such as tumor necrosis factor $\alpha(\mathrm{TNF} \alpha)$, and amplification of the proinflammatory response is mediated by activation of the NF- $\kappa \mathrm{B}$ and p38 MAPK pathways (Sunahori et al., 2006). A genomewide comparative bioinformatics analysis of gene expression in monocytes stimulated with S100A8 revealed overexpression of specific functional clusters related to the inflammatory response, leukocyte activation, cell migration, and the NF-кB signal transduction pathway (Fassl et al., 2015). Recombinant S100A9 induces the transcription of proinflammatory mediators in macrophages, and the response can be blocked by a RAGE antagonist or S100A9 silencing (Kawakami et al., 2020).

In addition to its proinflammatory effects, S100A8/A9 may have significant regulatory effects on inflammation as well. For example, treatment of phagocytes with S100A8/A9 for $24 \mathrm{~h}$ can induce a state of hyporesponsiveness in a TLR-4dependent manner (Austermann et al., 2014). S100A8/A9 also inhibits the maturation and antigen-presenting capabilities of dendritic cells (DCs), leading to a decreased T cell response and thus avoiding excessive adaptive immune responses (Petersen et al., 2013). Surprisingly, S100A8/A9 intensifies the population and activity of myeloid-derived suppressor cells (MDSCs), a heterogeneous group of cells that are immunosuppressive during many pathological conditions (Veglia et al., 2018). S100A8/A9 can disrupt overexpansion of the neonatal-specific inflammatory monocyte population, thus protecting against death from septic shock (Heinemann et al., 2017).

\section{S100A8/A9 IN MI}

The pathological process of MI is dynamic, including two successive stages: the early inflammatory stage and later the reparatory stage. The effective improvement of cardiac performance and a good patient prognosis depend on a satisfactory balance between these two phases (Prabhu and Frangogiannis, 2016). Hence, any immunomodulatory intervention in MI has to reach the appropriate balance between successful remission of excessive inflammatory responses and reasonable preservation of reparatory regulation.

In response to ischemic injury, neutrophil recruitment immediately increased within $6 \mathrm{~h}$ and peaked within $24 \mathrm{~h}$ during a 15-day observation period (Sreejit et al., 2020). Monocytes at the infarct site represent bi-phasic participation identified by early recruitment of proinflammatory Ly6 $\mathrm{C}^{\text {hi }}$ cells, which peak at day 3 and exert phagocytic and proteolytic functions, and late accumulation of anti-inflammatory Ly6 $\mathrm{C}^{\text {lo }}$ monocytes, which peak at day 5 and promote angiogenesis and collagen deposition (Nahrendorf et al., 2007; Dutta and Nahrendorf, 2015; Sreejit et al., 2020). The early perspective that neutrophils and monocytes are only implicated in the pathophysiology of the inflammatory stage has been challenged by researches indicating that these cells also orchestrate the reparative phases post-MI (Hilgendorf et al., 2014; Horckmans et al., 2017). S100A8/A9 continuously works to regulate the inflammatory and reparatory stages of $\mathrm{MI}$ and mainly acts in the migration and differentiation of immune cells, performing an increasingly vital role in the process of $\mathrm{MI}$. 


\section{Cellular Source of S100A8/A9 in MI}

Cardiac release of inflammatory cytokines and hypoxia are traits of MI and play pivotal roles in the pathogenesis of ischemic injury (Neumann et al., 1995). Enhanced secretion of S100A8/A9 in a hypoxic environment may be mediated by hypoxia-induced factor 1 (HIF-1), as HIF-1 was reported to upregulate transcriptional levels of S100A8/A9 in prostate cancer cells by directly activating the S100A8 and S100A9 promoters (Grebhardt et al., 2012). Further confirmation of the engagement of HIF-1 in the upregulation of S100A8/A9 was derived from Ahn et al. (2014), who proposed that HIF-1 upregulates S100A8 protein levels in monocytes.

Immune cells recruited from the circulation to the heart and the cardiomyocytes (CMs) themselves are important cellular constituents dedicated to the generation of cytokines in the heart during myocardial injury. Understanding the cellular origin of S100A8 and S100A9 may elucidate the importance of the mechanism underlying the pathological process of MI. Several types of cells were considered to be the sources of S100A8 and S100A9 production and release during MI, including neutrophils, macrophages, activated platelets, endothelial cells, and so on.

Actually, Du et al. (2012) did not discover any traces of S100A8 and S100A9 at any time point in neonatal Wistar rat CMs undergoing hypoxia, which is a critical feature of ischemic myocardial injury, indicating that $\mathrm{CMs}$ were not the origin of the elevated serum S100A8/A9 following MI. This study was not consistent with previous research showing that hypoxia treatment directly induced S100A8/A9 expression in prostate cancer cells (Grebhardt et al., 2012). Next, we examined whether the inflammatory immune cells infiltrating the heart are the sources of these proteins. Katashima et al. (2010) reported a positive correlation between serum S100A8/A9 levels and neutrophil counts that were dynamically monitored in AMI patients. The above research was further confirmed by another study describing that blood neutrophils as the only cell population independently and strongly influenced the circulating S100A8/A9 concentration in humans (Cotoi et al., 2014). Subsequently, Katashima et al. (2010) used double immunostaining to evaluate the infarcted heart in patients with AMI and demonstrated that S100A8/A9 complex mainly colocalized with neutrophils in infarcted myocardium during the early acute phase and highly colocalized with macrophages during the subacute phase, which was consistent with the findings of Rammes et al. (1997) and Boussac and Garin (2000). Another study also revealed that the synthesis and expression of S100A8/A9 were observably elevated in macrophages isolated from human bone marrow (BM) following hypoxia-ischemia in a time-dependent manner (Shi and Yi, 2018). More recently, Sreejit et al. (2020) applied cell sorting and flow cytometry to enrich $\mathrm{CD} 45^{+}$leukocytes from the infarcted heart in mice induced by permanent ligation of the left anterior descending (LAD) artery and found that neutrophils were the predominant source of S100A8/A9. This discrepancy may be explained by inconsistent time points of detection. Additionally, previous studies have shown that blood constituents such as platelets from patients with acute ST-segment-elevation MI (STEMI) could be reservoirs of S100A8 and S100A9 (Healy et al., 2006; Morrow et al., 2008).
However, the abundance of S100A8/A9 proteins in platelets was almost negligible in comparison with that in neutrophils after MI (Sreejit et al., 2020).

Taken together, these findings indicate that neutrophils and macrophages infiltrating the infarcted myocardium contribute significantly as the main sources of the increased S100A8/A9 concentration in cardiac tissue following AMI.

\section{Short-Term S100A9 Blockade Improves Cardiac Function}

S100A8/A9 provides an important first signal for inducing the hematopoietic response in the BM by directly interacting with RAGE on common myeloid progenitor cells in diabetes (Nagareddy et al., 2013) or through TLR-4-mediated mechanisms in obesity (Nagareddy et al., 2014). In response to MI, neutrophils abundantly expressing the specific alarmin S100A8/A9 rapidly traffic to the ischemic myocardium. Neutrophilderived S100A8/A9 subsequently interacts with TLR-4 on cardiac/circulating neutrophils, priming the nucleotide-binding oligomerization domain-like receptor protein 3 (NLRP3) inflammasome in neutrophils and facilitating the secretion of interleukin (IL) 1 (IL-1 $\beta$ ) in murine models of MI (Sreejit et al., 2020). The released IL-1 binds to IL-1 receptor type 1 (IL-1R1) on hematopoietic stem cells (HSCs) and hematopoietic progenitor cells (HPCs) in the BM, which in turn stimulates the differentiation of these cells into granulocytes in a cell-intrinsic fashion (Sager et al., 2015). The recognition that S100A8/A9 is an upstream event in MI-induced granulopoiesis was further supported by a mouse model with targeted interference of S100A9, in which genetic deletion of S100A9 or pharmacological blockade of S100A8/A9 with ABR-215757 notably constrained granulopoiesis with decreased numbers of neutrophils and monocytes in the circulation and heart and a reduced number of granulocyte precursors in the BM, as well as apparent downregulation of NLRP3 and IL-1 $\beta$ transcripts in cardiac neutrophils (Sreejit et al., 2020). In response to ischemic injury, neutrophils facilitate the proliferation and differentiation of BM-derived cells by secreting IL- $1 \beta$, which is mediated by S100A8/9, and medullary granulopoiesis is activated to satisfy the excessive recruitment and demand for neutrophils in the infarcted heart (Figure 1).

S100A8/A9 is a potent stimulator of neutrophils and enhances neutrophil chemotaxis and migration (Ryckman et al., 2003; Vogl et al., 2004). Intravenous injection of S100A8/A9 stimulates massive mobilization of neutrophils from the $\mathrm{BM}$ into the circulation and directs their migration to the inflammatory site (Vandal et al., 2003). S100A8/A9-mediated enhanced infiltration of immune cells at the infarct area may be attributed to the effect of S100A8/A9 in regulating adhesion by upregulating the expression of the leukocyte $\beta_{2}$ integrin Mac-1 (CD11b/CD18, aMB2) (Bouma et al., 2004; Scott et al., 2020). The binding of S100A8/A9 to TLR-4 brings about MyD88-induced small GTPase Rap1 activation and subsequently leads to $\beta 2$ integrin upregulation (Pruenster et al., 2015). Mac-1 is the most important $\beta_{2}$ integrin on the surface of neutrophils and mediates the recruitment of neutrophils across vascular endothelial cells to 


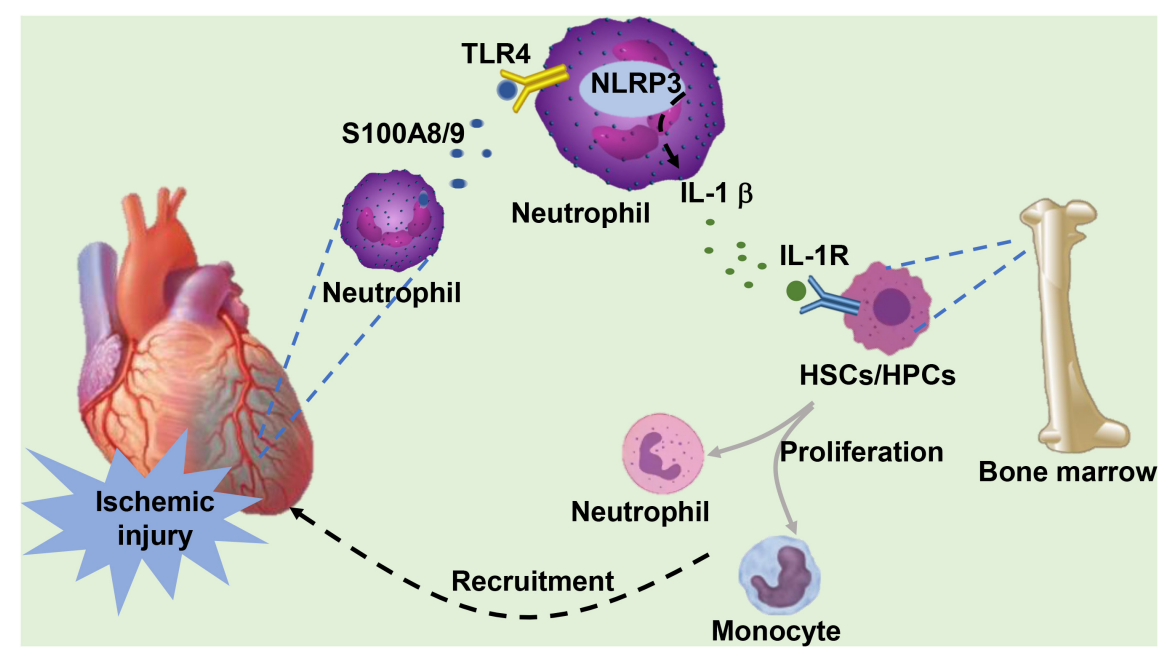

FIGURE 1 | Under ischemic injury, neutrophils infiltrating the heart secrete S100A8/A9. S100A8/A9 binds to TLR-4 on the surface of cardiac or circulating neutrophils, subsequently activating the formation of downstream NLRP3 and stimulating the release of IL-1 $\beta$. IL-1 binds to IL-1R on the surface of hematopoietic stem cells (HSCs) and hematopoietic progenitor cells (HPCs) in the bone marrow, which stimulates the proliferation and differentiation of HSCs into neutrophils and monocytes. These cells are eventually recruited to the infarcted heart in response to ischemic injury.

the inflammation site through interacting with intercellular cell adhesion molecule-1 (ICAM-1). Thus, a positive feedback loop is formed between the generation of S100A8/A9 and the infiltration of inflammatory cells in the ischemic myocardium.

Blockade S100A9 for short-term during the first 3 days postMI with the specific blocker ABR-238901, which inhibits the binding between S100A9 and its receptors (TLR-4 and RAGE) (Bjork et al., 2009), decreases neutrophils and macrophages infiltrating in the ischemic myocardium (Marinkovic et al., 2019). Elevated serum neutrophils and monocytes have been associated with left ventricular dysfunction, which is an independent and strong predictor of adverse prognoses in MI patients (Barron et al., 2001; Maekawa et al., 2002). Short-term blockade of S100A9 improves cardiac performance in mice with $\mathrm{MI}$, as shown by a trend toward increased left ventricular ejection fraction and cardiac output, a reduced percentage of apoptotic cells and a diminished infarction scar size (Marinkovic et al., 2019). These data were further verified by work from Sreejit et al. (2020), who described the significant improvement in cardiac performance in mice transplanted with BM from S100A9-/- mice. The improvement in cardiac function and mitigation of the local and systemic inflammatory response might be ascribed to S100A9 blockade-mediated suppression of inflammatory immune cell accumulation. Additionally, the binding of S100A8/A9 to TLR-4 leads to translocation of NF- $\mathrm{B}$ into the nucleus via TIR domain-containing adaptor inducing interferon- $\beta$ (TRIF)-dependent pathway or myeloid differentiation factor 88 (MyD88)-dependent pathway and consequently results in upregulating production of pro-inflammatory cytokines (Pruenster et al., 2016), which further amplifies the inflammatory response. On the other hand, cluster of differentiation 68 (CD68) expressed on macrophages probably serves as a receptor-like protein for extracellular S100 proteins. S100A8 and S100A9 proteins bind to CD68 with sugar chains and form CD68-S100A8 and CD68-S100A9 complexes with the molecule, whereby affecting immune functions of macrophages via an autocrine signal transduction pathway and consequently upregulating the expression of proinflammatory cytokines, especially IL-6 and TNF-a (Okada et al., 2016). Short-term S100A9 blockade decreases cytokine expression in inflammatory macrophages and increases the expression of signature genes associated with a reparatory macrophage phenotype, providing a reparatory microenvironment in the ischemic myocardium (Marinkovic et al., 2019). S100A8/9 plays a detrimental role in the early stage of MI, and therapeutic strategies to block S100A8/A9 will benefit patients with MI.

\section{Extended S100A9 Blockade Promote Adverse Cardiac Remodeling in MI}

In striking contrast to the benefits of short-term treatment for 3 days, extended S100A9 blockade for 21 days results in the acceleration of left ventricular remodeling and progressive deterioration of cardiac function (Marinkovic et al., 2020). These contradictory findings might be explained by the different functions of S100A9 in different pathological processes of the same disease.

The HSC subset expressing the MCP-1 receptor CCR2 has been identified to be one of the most upstream contributors to ischemic injury and has an important effect on myocardial healing (Dutta et al., 2015). However, sustained S100A9 blockade inhibits the proliferation of HSCs and HPCs in the BM, blunts the transition from $\mathrm{CCR}^{-}$to $\mathrm{CCR} 2^{+} \mathrm{HSCs}$, and hampers phagocyte egress from the BM (Marinkovic et al., 2019 , 2020). Post-MI, the differentiation of inflammatory Ly6C $\mathrm{C}^{\text {hi }}$ monocytes into reparatory Ly6 $\mathrm{C}^{\text {lo }}$ monocytes or reparatory F4/80 ${ }^{+}$Ly6C $^{\text {lo }}$ macrophages is mediated by the transcription factor NR4A1 (Nur77) (Hanna et al., 2011; Hilgendorf et al., 2014; 


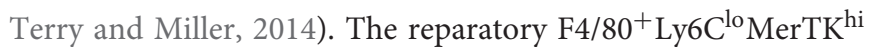
macrophages present in the myocardium during the reparatory phase after ischemic injury clear the accumulated apoptotic CMs via efferocytosis (Wan et al., 2013). Pharmacological blockade of S100A9 in the long term leads to reduced number of reparatory macrophage populations in the ischemic heart (Marinkovic et al., 2020). The decrease in reparatory macrophages in the post-ischemic myocardium and the impairment of phenotype transition from Ly6C $^{\text {hi }}$ to Ly6C ${ }^{\text {lo }}$ macrophages may be explained by S100A9 blockade-mediated Nur77 inhibition in mice, as S100A9 upregulates the expression and activity of Nur77 (Marinkovic et al., 2020). Furthermore, the continuous blockade of S100A9 into the reparatory phase also inhibits the mobilization of monocytes from the splenic reservoir to the ischemic myocardium and hinders their transformation into reparatory macrophages (Marinkovic et al., 2020) (Figure 2). The role of S100A9 in the repair period of MI was further confirmed by another experiment in which a reduction in infiltrating monocytes and macrophages in the myocardium with an approximately 50\% decrease in the number of reparatory Ly6 $\mathrm{C}^{\text {lo }}$ MerTK $^{\text {hi }}$ macrophages was detected in S100A9 gene-deficient mice (Marinkovic et al., 2020). Additionally, S100A8/S100A9 complex binds to cluster of differentiation 69 (CD69) in monocyte and forms CD69-S100A8/S100A9 association which positively regulates Treg-cell differentiation through the inhibition of signal transducer and activator of transcription 3 (STAT3) signaling by upregulation of suppressors of cytokine signaling 3 (SOCS3) expression (Lin et al., 2015). This function of S100A8/S100A9 complex likely causes immunosuppression of many immune cells and avoids excessive immune response. However, excessive blockade of S100A8/A9 probably abolish this beneficial effect during the reparatory phase of $\mathrm{MI}$.

Long-term S100A9 blockade with ABR-238901 in mice with myocardial ischemia results in progressive left ventricular remodeling and gradual deterioration of cardiac function, indicating additional cardioprotective effects of S100A8/A9 by polarizing macrophages toward a reparative phenotype during the recovery phase post-MI. These data support customized therapeutic strategies for short-term anti-S100A9 blockade during the early inflammatory phase post-MI, while long-term blockade affects the recovery of cardiac function during the reparatory phase; therefore, it is necessary to determine an appropriate therapeutic window.

\section{S100A8/A9 Aggravates Ischemia/Reperfusion (I/R) Injury}

Currently, the reperfusion strategy is widely accepted as an effective and standard therapy for STEMI (Vogel et al., 2019). Reperfusion can paradoxically protect the ischemic heart from developing myocardial necrosis, but it also initiates a series of cascade reactions that can exacerbate and prolong postischemic injury (Hausenloy and Yellon, 2016). The inflammatory response (Marinkovic et al., 2019), oxidative stress (Ferrari et al., 2004), and mitochondrial dysfunction (Walters et al., 2012) have long been regarded as critical pathophysiological phenomena

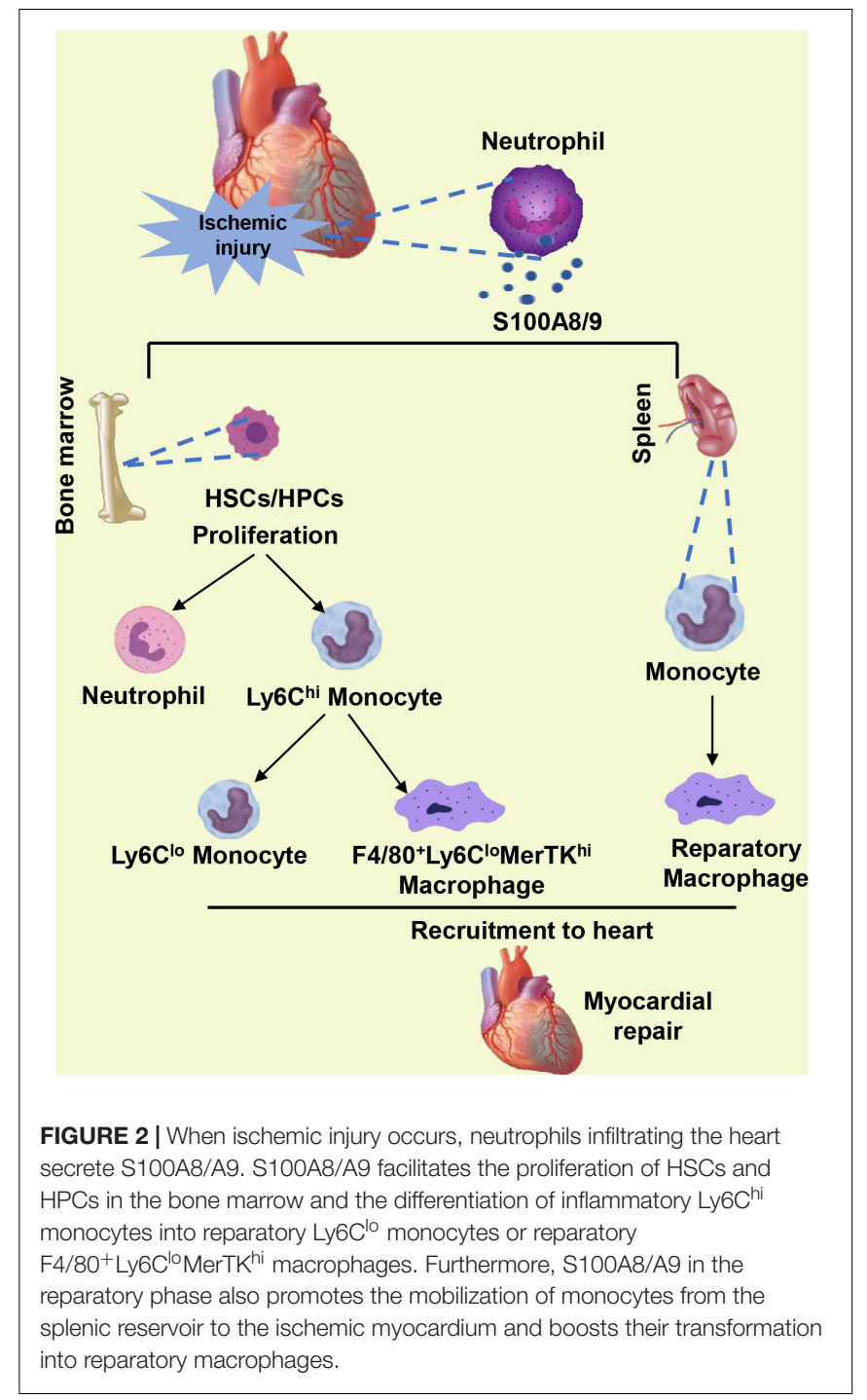

contributing to cardiac structural and functional alterations after ischemia/reperfusion (I/R) injury.

A seminal paper by Li et al. (2019) identified that S100A8/A9 expression was sustained in the heart in mice after I/R throughout the early stage of $\mathrm{I} / \mathrm{R}$, peaking at $6 \mathrm{~h}$ after reperfusion and returning to baseline at day 7 , as determined by time-series transcriptomics analysis. To fully understand the mechanism of $\mathrm{S} 100 \mathrm{~A} 8 / \mathrm{A} 9$ in $\mathrm{I} / \mathrm{R}$, it is also important to clarify the cellular sources of S100A8/A9 during reperfusion injury. Li et al. (2019) found that CXCR2 ${ }^{+}$neutrophils were the major sources of S100A8/A9 secretion, as the dynamic changes in $\mathrm{CXCR}^{+}{ }^{+}$neutrophil infiltration of the heart during $\mathrm{I} / \mathrm{R}$ were consistent with the pattern of S100A8/A9 expression, which were further confirmed by the fact that cardiac S100A8/A9 expression was substantially reduced in CXCR2-KO mice. Chemokine (C-X-C motif) ligand 1 (CXCL1), a specific chemokine for CXCR2, is responsible for the recruitment of neutrophils expressing the chemokine receptor CXCR2 into the inflammatory microenvironment (Drummond et al., 2019). 


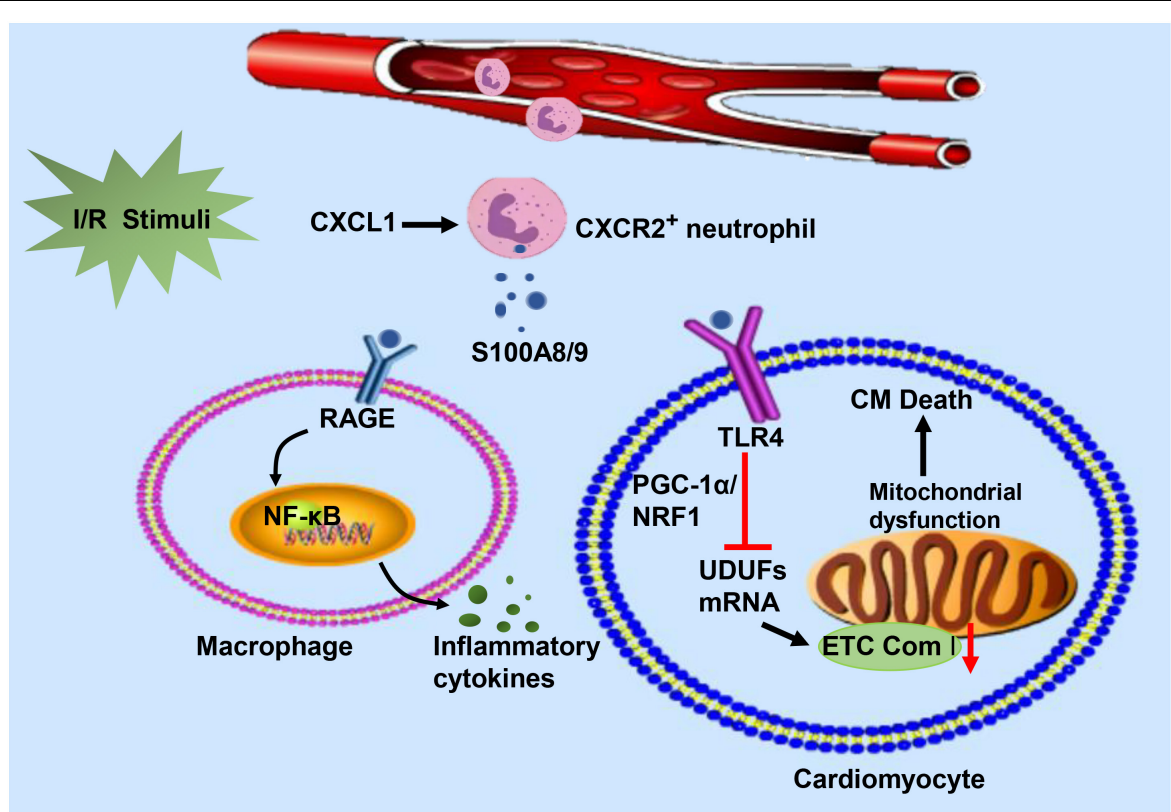

FIGURE 3 | In response to I/R injury, neutrophils migrate from the circulation to the injured heart in response to CXCL and release S100A8/A9. The heterodimeric complex binds to RAGE on the surface of immune cells and stimulates immune cells to secrete inflammatory cytokines by activating the NF- $\mathrm{B}$ signaling pathway. On the other hand, S100A8/A9 interacts with TLR-4 to inhibit NDUFs gene expression by suppressing the PGC-1/NRF1 signaling pathway, which decreases cardiac mitochondria electron transport chain (ETC) complex I activity. Mitochondrial dysfunction eventually leads to the death of cardiomyocytes.

Loss-of function and gain-of-function studies further demonstrated the significant function of S100A8/A9 in cardiac I/R. Ubiquitous S100A9 KO mice exhibited a simultaneous deletion of S100A8 and S100A9 (Cheng et al., 2008), probably owing to increased degradation of S100A8 protein in the loss of its dimerization partner S100A9, as S100A8 protein stability is highly dependent on the presence of S100A9 (Hobbs et al., 2003; Manitz et al., 2003). More recently, a study demonstrated that infarct size was significantly decreased, cardiac contractile function was improved, CM death was markedly reduced, and myocardial fibrosis was lessened in mice with global S100A9 deficiency following I/R (Li et al., 2019), which suggests a detrimental role of S100A9. Furthermore, a significantly reduced infarct region, increased cardiac function, and decreased myocardial fibrosis were observed post-I/R in mice treated with a S100A9 neutralizing antibody (nAb) (Li et al., 2019). Strong proof for the unfavorable effect of S100A9 in I/R injury stems from Marinkovic et al. (2019), who observed an efficient improvement in cardiac function in mice with short-term S100A9 blockade after I/R.

In contrast, transgenic mice with BM-specific overexpression of S100A9 exhibited an increase in infarct size, exacerbation of cardiac contractile function, enrichment in CM death and amplification of cardiac fibrosis (Li et al., 2019). Additional intraperitoneal treatment of mice with $\mathrm{I} / \mathrm{R}$ injury with human recombinant S100A8/A9 proteins (rS100A8/A9) resulted in observably raising influx of inflammatory immune cells into the myocardial ischemic zone and extensive interstitial collagen deposition, which further promoted maladaptive myocardial remodeling (Volz et al., 2012).
It is accepted that the S100A8/A9 heterodimeric complex, a well-known extracellular ligand, interacts with TLR-4 or RAGE, inducing diverse intracellular signaling cascades (Pruenster et al., 2016). The binding of S100A8/A9 and TLR-4 activates the Erk signaling pathway and subsequently inhibits the PGC- $1 \alpha / \mathrm{NRF} 1$ axis, which in turn downregulates the gene transcription of mitochondrial electron transport chain (ETC) complex I subunits (NDUFs) (Li et al., 2019). Mitochondrial dysfunction leads to impaired ATP biosynthesis disorders. Insufficient ATP synthesis is particularly detrimental to the heart because it requires enough energy to maintain normal activity. Moreover, a significant upregulation of RAGE results in sustained NF$\kappa \mathrm{B}$ activation (Andrassy et al., 2006), triggering a continuous inflammatory response and generating key proinflammatory mediators. S100A8/A9 might stimulate this positive feedback loop by engaging with RAGE (Kawakami et al., 2020), driving adverse cardiac remodeling post I/R. Upon ligation with its various receptors, S100A8/A9 can regulate CM death and cytokine release from innate immune cells in response to $I / R$ injury (Figure 3).

\section{CLINICAL RESEARCH ON S100A8/A9 IN MI}

There are increasing experimental studies and clinical evidence indicating that S100A8/A9 may favor the development of atherosclerosis (McCormick et al., 2005; Miyamoto et al., 2008). Clinical study in acute STEMI patients has confirmed that platelet and S100A8/A9 heterodimer were colocalized in coronary 
TABLE 1 | Clinic research on S100A8/A9 in MI.

\begin{tabular}{|c|c|c|}
\hline Authors & Clinic studies & References \\
\hline Healy et al. & $\begin{array}{l}\text { S100A9 mRNA levels in patients with } \\
\text { STEMI were elevated. }\end{array}$ & $\begin{array}{l}\text { Healy et al., } \\
2006\end{array}$ \\
\hline Shi et al. & $\begin{array}{l}\text { Serum S100A8/A9 levels were } \\
\text { increased in AMI patients and were } \\
\text { more pronounced in patients with } \\
\text { cardiac rupture. }\end{array}$ & $\begin{array}{l}\text { Shi and Yi, } \\
2018\end{array}$ \\
\hline Katashima et al. & $\begin{array}{l}\text { The circulating S100A8/A9 levels } \\
\text { reached a peak on days } 3-5 \text { after } \\
\text { ischemic injury and continued to } \\
\text { increase for several weeks after the } \\
\text { event. }\end{array}$ & $\begin{array}{l}\text { Katashima } \\
\text { et al., } 2010\end{array}$ \\
\hline Altwegg et al. & $\begin{array}{l}\text { Circulating S100A8/A9 levels were } \\
\text { elevated in patients with AMl and its } \\
\text { occurrence before classic myocardial } \\
\text { damage markers. }\end{array}$ & $\begin{array}{l}\text { Altwegg et al., } \\
2007\end{array}$ \\
\hline Vora et al. & $\begin{array}{l}\text { A single center prospective cohort } \\
\text { study indicated that S100A8/A9 was a } \\
\text { poor diagnostic marker with a } \\
\text { sensitivity of } 28 \% \text { for } \mathrm{MI} \text { in patients with } \\
\text { non-traumatic chest pain. }\end{array}$ & $\begin{array}{l}\text { Vora et al., } \\
2012\end{array}$ \\
\hline Morrow et al. & $\begin{array}{l}\text { S100A8/A9 was increased in patients } \\
\text { with end point events (Ml or } \\
\text { cardiovascular death) and S100A8/A9 } \\
\text { was associated with a high risk of } \\
\text { recurrence of cardiovascular events. }\end{array}$ & $\begin{array}{l}\text { Morrow et al., } \\
2008\end{array}$ \\
\hline Marinkovic et al. & $\begin{array}{l}\text { The patients with high plasma } \\
\text { S100A8/A9 levels within } 24 \text { h of an } \\
\text { acute coronary event had higher risk of } \\
\text { hospitalization for a main diagnosis of } \\
\text { heart failure and reduced left ventricular } \\
\text { ejection fractions. }\end{array}$ & $\begin{array}{l}\text { Marinkovic } \\
\text { et al., } 2019\end{array}$ \\
\hline Li et al. & $\begin{array}{l}\text { Patients with elevated serum } \\
\text { S100A8/A9 levels } 1 \text { day post-PCI were } \\
\text { more likely to undergo major adverse } \\
\text { cardiovascular events (MACEs). }\end{array}$ & Li et al., 2019 \\
\hline Cotoi et al. & $\begin{array}{l}\text { The circulating S100A8/A9 } \\
\text { concentration was positively correlated } \\
\text { with traditional cardiovascular risk } \\
\text { factors and circulating S100A8/A9 } \\
\text { levels could effectively predict the future } \\
\text { risk of the events of coronary artery } \\
\text { disease and cardiovascular death. }\end{array}$ & $\begin{array}{l}\text { Cotoi et al., } \\
2014\end{array}$ \\
\hline
\end{tabular}

artery thrombus. It was found that S100A9 binding to the scavenger receptor CD36 induces platelet activation via a signal cascade of VAV and JNK phosphorylation, thereby accelerating thrombosis (Wang et al., 2014). More interestingly, S100A8 and S100A9 protein and mRNA expression were also measured in macrophages and foam cells of atherosclerotic plaques from human carotid and aortic specimens (McCormick et al., 2005). In addition, the level of S100A9 in plaques was positively correlated with IL-6, IL-8, matrix metalloproteinase (MMP)-8, and MMP9 levels and negatively correlated with MMP-2 concentration (Ionita et al., 2009). These factors facilitate extracellular matrix degradation; therefore, atherosclerotic plaques are prone to rupture. Hence, S100A8/A9 is closely related to atherosclerosis, which is the underlying cause and pathological foundation of MI.

Healy et al. (2006) used transcriptional profiling analysis to identify S100A8/A9 as a novel predictor of MI by examining
TABLE 2 | Currently available possibilities to neutralize S100A8/A9.

\begin{tabular}{|c|c|c|}
\hline Strategy & Biological action & References \\
\hline ABR-238901 & $\begin{array}{l}\text { Block the binding of } \\
\text { S100A8/A9 to TLR4 and RAGE }\end{array}$ & $\begin{array}{l}\text { Marinkovic et al., 2019, } \\
2020\end{array}$ \\
\hline $\begin{array}{l}\text { Tasquinimod } \\
\text { (ABR-215050) }\end{array}$ & $\begin{array}{l}\text { Block the binding of } \\
\text { S100A8/A9 to TLR4 and RAGE }\end{array}$ & $\begin{array}{l}\text { Kallberg et al., 2012; } \\
\text { Raymond et al., } 2014\end{array}$ \\
\hline $\begin{array}{l}\text { Paquinimod } \\
\text { (ABR-215757) }\end{array}$ & $\begin{array}{l}\text { Block the binding of } \\
\text { S100A8/A9 to TLR4 and RAGE }\end{array}$ & $\begin{array}{l}\text { Wache et al., 2015; } \\
\text { Kraakman et al., } 2017\end{array}$ \\
\hline 43/8 Antibody & $\begin{array}{l}\text { Block the binding of } \\
\text { S100A8/A9 to TLR4 and RAGE }\end{array}$ & Bjork et al., 2009 \\
\hline $\begin{array}{l}\text { Anti-S100A9 lgG } \\
\text { antibody }\end{array}$ & $\begin{array}{l}\text { Neutralizes extracellular } \\
\text { S100A9 }\end{array}$ & Foronjy et al., 2016 \\
\hline $\begin{array}{l}\text { S100A9 small } \\
\text { interfering RNA }\end{array}$ & Silence S100A9 expression & New et al., 2013 \\
\hline $\begin{array}{l}\text { Genetic ablation of } \\
\text { S100A9 }\end{array}$ & Knockout S100A8 and S100A9 & $\begin{array}{l}\text { Schelbergen et al., } \\
\text { 2016; Vogl et al., 2018; } \\
\text { Li et al., } 2019\end{array}$ \\
\hline Narciclasine & $\begin{array}{l}\text { Reduced the plasma levels of } \\
\text { S100A8/A9 }\end{array}$ & Kingsley et al., 2020 \\
\hline
\end{tabular}

platelet mRNA transcripts and showed that S100A9 mRNA levels in patients with STEMI were strikingly elevated compared to those of patients with stable coronary artery disease. Published data from Shi and Yi (2018) also reported that serum S100A8/A9 levels were increased in AMI patients and were more pronounced in patients with cardiac rupture. Further, Katashima et al. reported on the dynamic monitoring of circulating S100A8/A9 levels in patients with AMI and unstable angina pectoris (UAP) in the acute phase. Compared with those of UAP patients, the early circulating S100A8/A9 levels of AMI patients were lower. At 3-5 days, the circulating S100A8/A9 levels of patients with AMI were significantly higher than those of patients with UAP. The circulating S100A8/A9 levels reached a peak on days 3-5 after ischemic injury and continued to increase for several weeks after the event (Katashima et al., 2010). Additionally, a clinical study showed that compared with patients with stable angina pectoris or individuals with normal coronary artery morphology assessed by coronary angiography, circulating S100A8/A9 levels were highly elevated in patients with ACS. The occurrence of elevated plasma S100A8/A9 before classic myocardial damage markers such as myoglobin and troponin makes it a promising candidate for the diagnosis and prediction of ACS (Altwegg et al., 2007). However, a single center prospective cohort study indicated that S100A8/A9 was a poor diagnostic marker with a sensitivity of $28 \%$ for MI in patients with non-traumatic chest pain and did not offer supernumerary diagnostic value comparable to that of cardiac troponin (Vora et al., 2012).

S100A8/A9 is also valuable for predicting the risk of recurrence of cardiovascular events in patients with acute ischemia. A nested case-control study of PROVE IT-TIMI intensive lipid-lowering therapy for ACS was performed to examine follow-up of patients after 30 days of acute cardiovascular events and found that S100A8/A9 was increased in patients with end point events (MI or cardiovascular death). Patients with S100A8/A9 values in the highest quartile had 2.0-fold increased odds of developing a recurrent cardiovascular 
event compared with those in the lowest quartile after adjusting for high-sensitivity C-reactive protein, hypertension, diabetes, previous cardiovascular disease, and heart failure (Morrow et al., 2008). The association between plasma S100A8/A9 levels and left ventricular dysfunction was studied in a cohort of 524 ACS patients. The patients with high plasma S100A8/A9 levels within $24 \mathrm{~h}$ of an acute coronary event had higher risk of hospitalization for a main diagnosis of heart failure and reduced left ventricular ejection fractions at 1 year after the MI (Marinkovic et al., 2019). Recently, a study enrolled 210 STEMI patients who received percutaneous coronary intervention (PCI) within $24 \mathrm{~h}$. Patients with elevated serum S100A8/A9 levels 1 day post-PCI were more likely to undergo major adverse cardiovascular events (MACEs), including cardiogenic shock, HF/rehospitalization, and cardiovascular mortality (Li et al., 2019). Furthermore, S100A8/A9 can also predict the risk of future cardiovascular events in healthy individuals. A study with a median followup of 16.2 years has shown that circulating S100A8/A9 levels could effectively predict the future risk of the events of coronary artery disease and cardiovascular death in a healthy female population. The circulating S100A8/A9 concentration was positively correlated with traditional cardiovascular risk factors, including glycosylated hemoglobin A1c, low-density lipoprotein, body mass index, and smoking (Cotoi et al., 2014).

Accordingly, this clinical evidence supports that S100A8/A9 is a feasible biomarker to distinguish patients with ACS from those with stable angina and that elevated circulating S100A8/A9 is clinically relevant to long-term adverse prognosis (Table 1).

\section{CONCLUSION}

Increased circulating S100A8/A9 levels are apparently associated with MI. However, the specific molecular mechanisms and pathways of S100A8/A9 underlying this acute event are now being elucidated. Given S100A8 KO mice are lethal and S100A9

\section{REFERENCES}

Ahmadi, A., Argulian, E., Leipsic, J., Newby, D. E., and Narula, J. (2019). From subclinical atherosclerosis to plaque progression and acute coronary events: JACC state-of-the-art review. J. Am. Coll. Cardiol. 74, 1608-1617. doi: 10.1016/ j.jacc.2019.08.012

Ahn, G. O., Seita, J., Hong, B. J., Kim, Y. E., Bok, S., Lee, C. J., et al. (2014). Transcriptional activation of hypoxia-inducible factor-1 (HIF1) in myeloid cells promotes angiogenesis through VEGF and S100A8. Proc. Natl. Acad. Sci. U.S.A. 111, 2698-2703. doi: 10.1073/pnas.132024 3111

Altwegg, L. A., Neidhart, M., Hersberger, M., Muller, S., Eberli, F. R., Corti, R., et al. (2007). Myeloid-related protein $8 / 14$ complex is released by monocytes and granulocytes at the site of coronary occlusion: a novel, early, and sensitive marker of acute coronary syndromes. Eur. Heart J. 28, 941-948. doi: 10.1093/ eurheartj/ehm078

Andrassy, M., Igwe, J., Autschbach, F., Volz, C., Remppis, A., Neurath, M. F., et al. (2006). Posttranslationally modified proteins as mediators of sustained intestinal inflammation. Am. J. Pathol. 169, 1223-1237. doi: 10.2353/ajpath. 2006.050713

Austermann, J., Friesenhagen, J., Fassl, S. K., Petersen, B., Ortkras, T., Burgmann, J., et al. (2014). Alarmins MRP8 and MRP14 induce stress tolerance in phagocytes
KO mice also lack S100A8 proteins, it remains a challenge to distinguish between the specific role of S100A9 and S100A8 proteins in MI. Currently, multiple available possibilities to neutralize S100A8/A9 have been indicated in various disease models (Table 2). These studies allow us to set further objective to explore the applicability of antibodies or compounds that block the binding of S100A8/A9 to CD molecules. In addition, therapeutic strategies for short-term anti-S100A9 blockade during the early inflammatory phase post-MI can effectively mitigated post-ischemic myocardial damage, while long-term blockade may induce undesired side effects and offset the favorable consequences of short-term treatment. Therefore, how to determine an appropriate therapeutic window to achieve optimal effects of S100A9 blockade will be a hot topic with research prospects in the future.

\section{AUTHOR CONTRIBUTIONS}

ZC and QT took charge of the design of the work. QX and TH were responsible for the collection of data. QY and JZ analyzed the data. ZC drafted the manuscript. ZC and QW reviewed and revised the manuscript. All authors contributed to the article and approved the submitted version.

\section{FUNDING}

This work was supported by grants from the National Natural Science Foundation of China (Nos. 81530012 and 81700353), National Key R\&D Program of China (2018YFC1311300), Development Center for Medical Science and Technology National Health and Family Planning Commission of the People's Republic of China (the prevention and control project of cardiovascular disease, 2016ZX-008-01), and the Fundamental Research Funds for the Central Universities (2042018kf1032).

under sterile inflammatory conditions. Cell Rep. 9, 2112-2123. doi: 10.1016/j. celrep.2014.11.020

Averill, M. M., Barnhart, S., Becker, L., Li, X., Heinecke, J. W., Leboeuf, R. C., et al. (2011). S100A9 differentially modifies phenotypic states of neutrophils, macrophages, and dendritic cells: implications for atherosclerosis and adipose tissue inflammation. Circulation 123, 1216-1226. doi: 10.1161/circulationaha. 110.985523

Aydin, S., Ugur, K., Aydin, S., Sahin, I., and Yardim, M. (2019). Biomarkers in acute myocardial infarction: current perspectives. Vasc. Health Risk Manag. 15, 1-10. doi: $10.2147 /$ vhrm.s166157

Barron, H. V., Harr, S. D., Radford, M. J., Wang, Y., and Krumholz, H. M. (2001). The association between white blood cell count and acute myocardial infarction mortality in patients $>$ or $=65$ years of age: findings from the cooperative cardiovascular project. J. Am. Coll. Cardiol. 38, 1654-1661. doi: 10.1016/s07351097(01)01613-8

Bjork, P., Bjork, A., Vogl, T., Stenstrom, M., Liberg, D., Olsson, A., et al. (2009). Identification of human S100A9 as a novel target for treatment of autoimmune disease via binding to quinoline-3-carboxamides. PLoS Biol 7:e97. doi: 10.1371/ journal.pbio. 1000097

Bouma, G., Lam-Tse, W. K., Wierenga-Wolf, A. F., Drexhage, H. A., and Versnel, M. A. (2004). Increased serum levels of MRP-8/14 in type 1 diabetes induce an increased expression of CD11b and an enhanced adhesion of circulating 
monocytes to fibronectin. Diabetes 53, 1979-1986. doi: 10.2337/diabetes.53.8. 1979

Boussac, M., and Garin, J. (2000). Calcium-dependent secretion in human neutrophils: a proteomic approach. Electrophoresis 21, 665-672. doi: 10.1002/ (sici) 1522-2683(20000201)21:3<665::aid-elps665>3.0.co;2-u

Boyd, J. H., Kan, B., Roberts, H., Wang, Y., and Walley, K. R. (2008). S100A8 and S100A9 mediate endotoxin-induced cardiomyocyte dysfunction via the receptor for advanced glycation end products. Circ. Res. 102, 1239-1246. doi: 10.1161/circresaha.107.167544

Bresnick, A. R., Weber, D. J., and Zimmer, D. B. (2015). S100 proteins in cancer. Nat. Rev. Cancer 15, 96-109. doi: 10.1038/nrc3893

Cheng, P., Corzo, C. A., Luetteke, N., Yu, B., Nagaraj, S., Bui, M. M., et al. (2008). Inhibition of dendritic cell differentiation and accumulation of myeloid-derived suppressor cells in cancer is regulated by S100A9 protein. J. Exp. Med. 205, 2235-2249. doi: 10.1084/jem.20080132

Cotoi, O. S., Duner, P., Ko, N., Hedblad, B., Nilsson, J., Bjorkbacka, H., et al. (2014). Plasma S100A8/A9 correlates with blood neutrophil counts, traditional risk factors, and cardiovascular disease in middle-aged healthy individuals. Arterioscler. Thromb. Vasc. Biol. 34, 202-210. doi: 10.1161/atvbaha.113.302432

Donato, R. (2001). S100: a multigenic family of calcium-modulated proteins of the EF-hand type with intracellular and extracellular functional roles. Int. J. Biochem. Cell Biol. 33, 637-668. doi: 10.1016/s1357-2725(01)00046-2

Donato, R. (2003). Intracellular and extracellular roles of S100 proteins. Microsc. Res. Tech. 60, 540-551. doi: 10.1002/jemt.10296

Donato, R., Cannon, B. R., Sorci, G., Riuzzi, F., Hsu, K., Weber, D. J., et al. (2013). Functions of S100 proteins. Curr. Mol. Med. 13, 24-57.

Doussiere, J., Bouzidi, F., and Vignais, P. V. (2001). A phenylarsine oxide-binding protein of neutrophil cytosol, which belongs to the S100 family, potentiates NADPH oxidase activation. Biochem. Biophys. Res. Commun. 285, 1317-1320. doi: 10.1006/bbrc.2001.5324

Doussiere, J., Bouzidi, F., and Vignais, P. V. (2002). The S100A8/A9 protein as a partner for the cytosolic factors of NADPH oxidase activation in neutrophils. Eur. J. Biochem. 269, 3246-3255. doi: 10.1046/j.1432-1033.2002.03002.x

Drummond, R. A., Swamydas, M., Oikonomou, V., Zhai, B., Dambuza, I. M., Schaefer, B. C., et al. (2019). CARD9(+) microglia promote antifungal immunity via IL-1beta- and CXCL1-mediated neutrophil recruitment. Nat. Immunol. 20, 559-570. doi: 10.1038/s41590-019-0377-2

Du, C. Q., Yang, L., Han, J., Yang, J., Yao, X. Y., Hu, X. S., et al. (2012). The elevated serum S100A8/A9 during acute myocardial infarction is not of cardiac myocyte origin. Inflammation 35, 787-796. doi: 10.1007/s10753-011-9375-8

Dutta, P., and Nahrendorf, M. (2015). Monocytes in myocardial infarction. Arterioscler. Thromb. Vasc. Biol. 35, 1066-1070. doi: 10.1161/atvbaha.114. 304652

Dutta, P., Sager, H. B., Stengel, K. R., Naxerova, K., Courties, G., Saez, B., et al. (2015). Myocardial Infarction Activates CCR2(+) hematopoietic stem and progenitor cells. Cell Stem Cell 16, 477-487.

Ehlermann, P., Eggers, K., Bierhaus, A., Most, P., Weichenhan, D., Greten, J., et al. (2006). Increased proinflammatory endothelial response to S100A8/A9 after preactivation through advanced glycation end products. Cardiovasc. Diabetol. 5:6.

Ehrchen, J. M., Sunderkotter, C., Foell, D., Vogl, T., and Roth, J. (2009). The endogenous Toll-like receptor 4 agonist S100A8/S100A9 (calprotectin) as innate amplifier of infection, autoimmunity, and cancer. J. Leukoc. Biol. 86, 557-566. doi: 10.1189/jlb.1008647

Fassl, S. K., Austermann, J., Papantonopoulou, O., Riemenschneider, M., Xue, J., Bertheloot, D., et al. (2015). Transcriptome assessment reveals a dominant role for TLR4 in the activation of human monocytes by the alarmin MRP8. J. Immunol. 194, 575-583. doi: 10.4049/jimmunol.1401085

Ferrari, R., Guardigli, G., Mele, D., Percoco, G. F., Ceconi, C., and Curello, S. (2004). Oxidative stress during myocardial ischaemia and heart failure. Curr. Pharm. Des. 10, 1699-1711. doi: 10.2174/1381612043384718

Foronjy, R. F., Ochieng, P. O., Salathe, M. A., Dabo, A. J., Eden, E., Baumlin, N., et al. (2016). Protein tyrosine phosphatase 1B negatively regulates S100A9mediated lung damage during respiratory syncytial virus exacerbations. Mucosal Immunol. 9, 1317-1329. doi: 10.1038/mi.2015.138

Frosch, M., Strey, A., Vogl, T., Wulffraat, N. M., Kuis, W., Sunderkotter, C., et al. (2000). Myeloid-related proteins 8 and 14 are specifically secreted during interaction of phagocytes and activated endothelium and are useful markers for monitoring disease activity in pauciarticular-onset juvenile rheumatoid arthritis. Arthritis Rheum 43, 628-637. doi: 10.1002/1529-0131(200003)43: $3<628$ ::aid-anr20>3.0.co; $2-\mathrm{x}$

Fuchs, T. A., Abed, U., Goosmann, C., Hurwitz, R., Schulze, I., Wahn, V., et al. (2007). Novel cell death program leads to neutrophil extracellular traps. J. Cell Biol. 176, 231-241. doi: 10.1083/jcb.200606027

Gonzalez, L. L., Garrie, K., and Turner, M. D. (2020). Role of S100 proteins in health and disease. Biochim. Biophys. Acta Mol .Cell Res. 1867:118677. doi: 10.1016/j.bbamcr.2020.118677

Goyette, J., and Geczy, C. L. (2011). Inflammation-associated S100 proteins: new mechanisms that regulate function. Amino Acids 41, 821-842. doi: 10.1007/ s00726-010-0528-0

Grebhardt, S., Veltkamp, C., Strobel, P., and Mayer, D. (2012). Hypoxia and HIF-1 increase S100A8 and S100A9 expression in prostate cancer. Int. J. Cancer 131, 2785-2794. doi: 10.1002/ijc.27591

Grimbaldeston, M. A., Geczy, C. L., Tedla, N., Finlay-Jones, J. J., and Hart, P. H. (2003). S100A8 induction in keratinocytes by ultraviolet A irradiation is dependent on reactive oxygen intermediates. J. Invest. Dermatol. 121, 11681174. doi: 10.1046/j.1523-1747.2003.12561.x

Hanna, R. N., Carlin, L. M., Hubbeling, H. G., Nackiewicz, D., Green, A. M., Punt, J. A., et al. (2011). The transcription factor NR4A1 (Nur77) controls bone marrow differentiation and the survival of Ly6C- monocytes. Nat. Immunol. 12, 778-785. doi: 10.1038/ni.2063

Hausenloy, D. J., and Yellon, D. M. (2016). Ischaemic conditioning and reperfusion injury. Nat. Rev. Cardiol. 13, 193-209. doi: 10.1038/nrcardio.2016.5

Healy, A. M., Pickard, M. D., Pradhan, A. D., Wang, Y., Chen, Z., Croce, K., et al. (2006). Platelet expression profiling and clinical validation of myeloid-related protein-14 as a novel determinant of cardiovascular events. Circulation 113, 2278-2284. doi: 10.1161/circulationaha.105.607333

Heinemann, A. S., Pirr, S., Fehlhaber, B., Mellinger, L., Burgmann, J., Busse, M., et al. (2017). In neonates S100A8/S100A9 alarmins prevent the expansion of a specific inflammatory monocyte population promoting septic shock. FASEB J. 31, 1153-1164. doi: 10.1096/fj.201601083r

Hessian, P. A., Edgeworth, J., and Hogg, N. (1993). MRP-8 and MRP-14, two abundant $\mathrm{Ca}(2+)$-binding proteins of neutrophils and monocytes. J. Leukoc. Biol. 53, 197-204. doi: 10.1002/jlb.53.2.197

Heusch, G., and Gersh, B. J. (2017). The pathophysiology of acute myocardial infarction and strategies of protection beyond reperfusion: a continual challenge. Eur. Heart J. 38, 774-784.

Hilgendorf, I., Gerhardt, L. M., Tan, T. C., Winter, C., Holderried, T. A., Chousterman, B. G., et al. (2014). Ly-6Chigh monocytes depend on Nr4al to balance both inflammatory and reparative phases in the infarcted myocardium. Circ. Res. 114, 1611-1622. doi: 10.1161/circresaha.114.303204

Hobbs, J. A., May, R., Tanousis, K., McNeill, E., Mathies, M., Gebhardt, C., et al. (2003). Myeloid cell function in MRP-14 (S100A9) null mice. Mol. Cell. Biol. 23, 2564-2576. doi: 10.1128/mcb.23.7.2564-2576.2003

Horckmans, M., Ring, L., Duchene, J., Santovito, D., Schloss, M. J., Drechsler, M., et al. (2017). Neutrophils orchestrate post-myocardial infarction healing by polarizing macrophages towards a reparative phenotype. Eur. Heart J. 38, 187-197.

Inaba, H., Hokamura, K., Nakano, K., Nomura, R., Katayama, K., Nakajima, A., et al. (2009). Upregulation of S100 calcium-binding protein A9 is required for induction of smooth muscle cell proliferation by a periodontal pathogen. FEBS Lett. 583, 128-134. doi: 10.1016/j.febslet.2008.11.036

Ingersoll, M. A., Spanbroek, R., Lottaz, C., Gautier, E. L., Frankenberger, M., Hoffmann, R., et al. (2010). Comparison of gene expression profiles between human and mouse monocyte subsets. Blood 115, e10-e19.

Ionita, M. G., Vink, A., Dijke, I. E., Laman, J. D., Peeters, W., van der Kraak, P. H., et al. (2009). High levels of myeloid-related protein 14 in human atherosclerotic plaques correlate with the characteristics of rupture-prone lesions. Arterioscler. Thromb. Vasc. Biol. 29, 1220-1227. doi: 10.1161/atvbaha.109.190314

Kallberg, E., Vogl, T., Liberg, D., Olsson, A., Bjork, P., Wikstrom, P., et al. (2012). S100A9 interaction with TLR4 promotes tumor growth. PLoS One 7:e34207. doi: 10.1371/journal.pone.0034207

Kalogeris, T., Baines, C. P., Krenz, M., and Korthuis, R. J. (2016). Ischemia/Reperfusion. Compr. Physiol. 7, 113-170.

Katashima, T., Naruko, T., Terasaki, F., Fujita, M., Otsuka, K., Murakami, S., et al. (2010). Enhanced expression of the S100A8/A9 complex in acute 
myocardial infarction patients. Circ. J. 74, 741-748. doi: 10.1253/circj.cj-090564

Kawakami, R., Katsuki, S., Travers, R., Romero, D. C., Becker-Greene, D., Passos, L. S. A., et al. (2020). S100A9-RAGE Axis Accelerates Formation of Macrophage-Mediated Extracellular Vesicle Microcalcification in Diabetes Mellitus. Arterioscler. Thromb. Vasc. Biol. 40, 1838-1853. doi: 10.1161/atvbaha. 118.314087

Kingsley, M. K., Bhat, B. V., Badhe, B. A., Dhas, B. B., and Parija, S. C. (2020). Narciclasine improves outcome in sepsis among neonatal rats via inhibition of calprotectin and alleviating inflammatory responses. Sci. Rep. 10:2947.

Kraakman, M. J., Lee, M. K., Al-Sharea, A., Dragoljevic, D., Barrett, T. J., Montenont, E., et al. (2017). Neutrophil-derived S100 calcium-binding proteins A8/A9 promote reticulated thrombocytosis and atherogenesis in diabetes. J. Clin. Invest. 127, 2133-2147. doi: 10.1172/jci92450

Landers-Ramos, R. Q., Sapp, R. M., VandeWater, E., Macko, J., Robinson, S., Wang, Y., et al. (2017). Investigating the extremes of the continuum of paracrine functions in CD34-/CD31+ CACs across diverse populations. Am. J. Physiol. Heart Circ. Physiol. 312, H162-H172.

Lesniak, W. (2011). Epigenetic regulation of S100 protein expression. Clin. Epigenetics 2, 77-83. doi: 10.1007/s13148-011-0023-9

Leukert, N., Sorg, C., and Roth, J. (2005). Molecular basis of the complex formation between the two calcium-binding proteins S100A8 (MRP8) and S100A9 (MRP14). Biol. Chem. 386, 429-434. doi: 10.1515/bc.2005.051

Leukert, N., Vogl, T., Strupat, K., Reichelt, R., Sorg, C., and Roth, J. (2006). Calcium-dependent tetramer formation of S100A8 and S100A9 is essential for biological activity. J. Mol. Biol. 359, 961-972. doi: 10.1016/j.jmb.2006.04.009

Li, Y., Chen, B., Yang, X., Zhang, C., Jiao, Y., Li, P., et al. (2019). S100a8/a9 signaling causes mitochondrial dysfunction and cardiomyocyte death in response to ischemic/reperfusion injury. Circulation 140, 751-764. doi: 10 . 1161/circulationaha.118.039262

Lin, C. R., Wei, T. Y., Tsai, H. Y., Wu, Y. T., Wu, P. Y., and Chen, S. T. (2015). Glycosylation-dependent interaction between CD69 and S100A8/S100A9 complex is required for regulatory T-cell differentiation. FASEB J. 29, 50065017. doi: 10.1096/fj.15-273987

Maekawa, Y., Anzai, T., Yoshikawa, T., Asakura, Y., Takahashi, T., Ishikawa, S., et al. (2002). Prognostic significance of peripheral monocytosis after reperfused acute myocardial infarction:a possible role for left ventricular remodeling. J. Am. Coll. Cardiol. 39, 241-246. doi: 10.1016/s0735-1097(01)01721-1

Manitz, M. P., Horst, B., Seeliger, S., Strey, A., Skryabin, B. V., Gunzer, M., et al. (2003). Loss of S100A9 (MRP14) results in reduced interleukin-8-induced CD11b surface expression, a polarized microfilament system, and diminished responsiveness to chemoattractants in vitro. Mol. Cell. Biol. 23, 1034-1043. doi: $10.1128 / \mathrm{mcb} .23 .3 .1034-1043.2003$

Marenholz, I., Heizmann, C. W., and Fritz, G. (2004). S100 proteins in mouse and man: from evolution to function and pathology (including an update of the nomenclature). Biochem. Biophys. Res. Commun. 322, 1111-1122. doi: 10.1016/j.bbrc.2004.07.096

Marinkovic, G., Grauen Larsen, H., Yndigegn, T., Szabo, I. A., Mares, R. G., de Camp, L., et al. (2019). Inhibition of pro-inflammatory myeloid cell responses by short-term S100A9 blockade improves cardiac function after myocardial infarction. Eur. Heart J. 40, 2713-2723. doi: 10.1093/eurheartj/ehz461

Marinkovic, G., Koenis, D., de Camp, L., Jablonowski, R., Graber, N., de Waard, V., et al. (2020). S100A9 links inflammation and repair in myocardial infarction. Circ. Res. 127, 664-676. doi: 10.1161/circresaha.120.315865

McCormick, M. M., Rahimi, F., Bobryshev, Y. V., Gaus, K., Zreiqat, H., Cai, H., et al. (2005). S100A8 and S100A9 in human arterial wall. Implications for atherogenesis. J. Biol. Chem. 280, 41521-41529. doi: 10.1074/jbc.m509442200

Miyamoto, S., Ueda, M., Ikemoto, M., Naruko, T., Itoh, A., Tamaki, S., et al. (2008). Increased serum levels and expression of S100A8/A9 complex in infiltrated neutrophils in atherosclerotic plaque of unstable angina. Heart 94, 1002-1007. doi: 10.1136/hrt.2007.121640

Moore, B. W. (1965). A soluble protein characteristic of the nervous system. Biochem. Biophys. Res. Commun. 19, 739-744. doi: 10.1016/0006-291x(65) 90320-7

Morrow, D. A., Wang, Y., Croce, K., Sakuma, M., Sabatine, M. S., Gao, H., et al. (2008). Myeloid-related protein $8 / 14$ and the risk of cardiovascular death or myocardial infarction after an acute coronary syndrome in the Pravastatin or Atorvastatin Evaluation and Infection Therapy: thrombolysis in Myocardial
Infarction (PROVE IT-TIMI 22) trial. Am. Heart J. 155, 49-55. doi: 10.1016/j. ahj.2007.08.018

Muller, I., Vogl, T., Kuhl, U., Krannich, A., Banks, A., Trippel, T., et al. (2020). Serum alarmin S100A8/S100A9 levels and its potential role as biomarker in myocarditis. ESC Heart Fail. 7, 1442-1451. doi: 10.1002/ehf2.12760

Muller, I., Vogl, T., Pappritz, K., Miteva, K., Savvatis, K., Rohde, D., et al. (2017). Pathogenic role of the damage-associated molecular patterns S100A8 and S100A9 in Coxsackievirus B3-Induced Myocarditis. Circ. Heart Fail. 10:e004125.

Nagareddy, P. R., Kraakman, M., Masters, S. L., Stirzaker, R. A., Gorman, D. J., Grant, R. W., et al. (2014). Adipose tissue macrophages promote myelopoiesis and monocytosis in obesity. Cell Metab. 19, 821-835. doi: 10.1016/j.cmet.2014. 03.029

Nagareddy, P. R., Murphy, A. J., Stirzaker, R. A., Hu, Y., Yu, S., Miller, R. G., et al. (2013). Hyperglycemia promotes myelopoiesis and impairs the resolution of atherosclerosis. Cell Metab. 17, 695-708. doi: 10.1016/j.cmet.2013.04.001

Nahrendorf, M., Swirski, F. K., Aikawa, E., Stangenberg, L., Wurdinger, T., Figueiredo, J. L., et al. (2007). The healing myocardium sequentially mobilizes two monocyte subsets with divergent and complementary functions. J. Exp. Med. 204, 3037-3047. doi: 10.1084/jem.20070885

Neumann, F. J., Ott, I., Gawaz, M., Richardt, G., Holzapfel, H., Jochum, M., et al. (1995). Cardiac release of cytokines and inflammatory responses in acute myocardial infarction. Circulation 92, 748-755. doi: 10.1161/01.cir.92.4.748

New, S. E., Goettsch, C., Aikawa, M., Marchini, J. F., Shibasaki, M., Yabusaki, K., et al. (2013). Macrophage-derived matrix vesicles: an alternative novel mechanism for microcalcification in atherosclerotic plaques. Circ. Res. 113, 72-77. doi: 10.1161/circresaha.113.301036

Newton, K., and Dixit, V. M. (2012). Signaling in innate immunity and inflammation. Cold Spring Harb. Perspect. Biol. 4:a006049.

Odink, K., Cerletti, N., Bruggen, J., Clerc, R. G., Tarcsay, L., Zwadlo, G., et al. (1987). Two calcium-binding proteins in infiltrate macrophages of rheumatoid arthritis. Nature 330, 80-82. doi: 10.1038/330080a0

Okada, K., Arai, S., Itoh, H., Adachi, S., Hayashida, M., Nakase, H., et al. (2016). CD68 on rat macrophages binds tightly to S100A8 and S100A9 and helps to regulate the cells' immune functions. J. Leukoc. Biol. 100, 1093-1104. doi: 10.1189/jlb.2a0415-170rrr

Otsuka, K., Terasaki, F., Ikemoto, M., Fujita, S., Tsukada, B., Katashima, T., et al. (2009). Suppression of inflammation in rat autoimmune myocarditis by S100A8/A9 through modulation of the proinflammatory cytokine network. Eur. J. Heart Fail. 11, 229-237. doi: 10.1093/eurjhf/hfn049

Passey, R. J., Williams, E., Lichanska, A. M., Wells, C., Hu, S., Geczy, C. L., et al. (1999). A null mutation in the inflammation-associated S100 protein S100A8 causes early resorption of the mouse embryo. J. Immunol. 163, 2209-2216.

Pei, X. M., Tam, B. T., Sin, T. K., Wang, F. F., Yung, B. Y., Chan, L. W., et al. (2016). S100A8 and S100A9 are associated with doxorubicin-induced cardiotoxicity in the heart of diabetic mice. Front. Physiol. 7:334.

Petersen, B., Wolf, M., Austermann, J., van Lent, P., Foell, D., Ahlmann, M., et al. (2013). The alarmin Mrp8/14 as regulator of the adaptive immune response during allergic contact dermatitis. EMBO J. 32, 100-111. doi: 10.1038/emboj. 2012.309

Prabhu, S. D., and Frangogiannis, N. G. (2016). The biological basis for cardiac repair after myocardial infarction: from inflammation to fibrosis. Circ. Res. 119, 91-112. doi: 10.1161/circresaha.116.303577

Pruenster, M., Kurz, A. R., Chung, K. J., Cao-Ehlker, X., Bieber, S., Nussbaum, C. F., et al. (2015). Extracellular MRP8/14 is a regulator of beta2 integrin-dependent neutrophil slow rolling and adhesion. Nat. Commun. 6:6915.

Pruenster, M., Vogl, T., Roth, J., and Sperandio, M. (2016). S100A8/A9: from basic science to clinical application. Pharmacol. Ther. 167, 120-131. doi: 10.1016/j. pharmthera.2016.07.015

Rahimi, F., Hsu, K., Endoh, Y., and Geczy, C. L. (2005). FGF-2, IL-1beta and TGF-beta regulate fibroblast expression of S100A8. FEBS J. 272, 2811-2827. doi: 10.1111/j.1742-4658.2005.04703.x

Rammes, A., Roth, J., Goebeler, M., Klempt, M., Hartmann, M., and Sorg, C. (1997). Myeloid-related protein (MRP) 8 and MRP14, calcium-binding proteins of the S100 family, are secreted by activated monocytes via a novel, tubulin-dependent pathway. J. Biol. Chem. 272, 9496-9502. doi: 10.1074/jbc.272.14.9496

Raymond, E., Dalgleish, A., Damber, J. E., Smith, M., and Pili, R. (2014). Mechanisms of action of tasquinimod on the tumour microenvironment. 
Cancer Chemother. Pharmacol. 73, 1-8. doi: 10.1007/s00280-0132321-8

Reed, G. W., Rossi, J. E., and Cannon, C. P. (2017). Acute myocardial infarction. Lancet 389, 197-210.

Ryckman, C., Vandal, K., Rouleau, P., Talbot, M., and Tessier, P. A. (2003). Proinflammatory activities of S100: proteins S100A8, S100A9, and S100A8/A9 induce neutrophil chemotaxis and adhesion. J. Immunol. 170, 3233-3242. doi: 10.4049/jimmunol.170.6.3233

Sager, H. B., Heidt, T., Hulsmans, M., Dutta, P., Courties, G., Sebas, M., et al. (2015). Targeting interleukin-1beta reduces leukocyte production after acute myocardial infarction. Circulation 132, 1880-1890. doi: 10.1161/circulationaha. 115.016160

Santamaria-Kisiel, L., Rintala-Dempsey, A. C., and Shaw, G. S. (2006). Calciumdependent and -independent interactions of the $\mathrm{S} 100$ protein family. Biochem. J. 396, 201-214. doi: 10.1042/bj20060195

Schafer, B. W., and Heizmann, C. W. (1996). The S100 family of EF-hand calciumbinding proteins: functions and pathology. Trends Biochem. Sci. 21, 134-140. doi: 10.1016/s0968-0004(96)80167-8

Schelbergen, R. F., de Munter, W., van den Bosch, M. H., Lafeber, F. P., Sloetjes, A., Vogl, T., et al. (2016). Alarmins S100A8/S100A9 aggravate osteophyte formation in experimental osteoarthritis and predict osteophyte progression in early human symptomatic osteoarthritis. Ann. Rheum Dis. 75, 218-225. doi: 10.1136/annrheumdis-2014-205480

Schiopu, A., and Cotoi, O. S. (2013). S100A8 and S100A9: DAMPs at the crossroads between innate immunity, traditional risk factors, and cardiovascular disease. Mediators Inflamm. 2013:828354.

Scott, N. R., Swanson, R. V., Al-Hammadi, N., Domingo-Gonzalez, R., RangelMoreno, J., Kriel, B. A., et al. (2020). S100A8/A9 regulates CD11b expression and neutrophil recruitment during chronic tuberculosis. J. Clin. Invest. 130, 3098-3112. doi: $10.1172 /$ jci130546

Shi, S., and Yi, J. L. (2018). S100A8/A9 promotes MMP-9 expression in the fibroblasts from cardiac rupture after myocardial infarction by inducing macrophages secreting TNFalpha. Eur. Rev. Med. Pharmacol. Sci. 22, 39253935.

Sreejit, G., Abdel-Latif, A., Athmanathan, B., Annabathula, R., Dhyani, A., Noothi, S. K., et al. (2020). Neutrophil-Derived S100A8/A9 amplify granulopoiesis after myocardial infarction. Circulation 141, 1080-1094. doi: 10.1161/circulationaha. 119.043833

Sunahori, K., Yamamura, M., Yamana, J., Takasugi, K., Kawashima, M., Yamamoto, H., et al. (2006). The S100A8/A9 heterodimer amplifies proinflammatory cytokine production by macrophages via activation of nuclear factor kappa $\mathrm{B}$ and p38 mitogen-activated protein kinase in rheumatoid arthritis. Arthritis Res. Ther. 8:R69.

Tardif, M. R., Chapeton-Montes, J. A., Posvandzic, A., Page, N., Gilbert, C., and Tessier, P. A. (2015). Secretion of S100A8, S100A9, and S100A12 by neutrophils involves reactive oxygen species and potassium efflux. J. Immunol. Res. 2015:296149.

Terry, R. L., and Miller, S. D. (2014). Molecular control of monocyte development. Cell. Immunol. 291, 16-21. doi: 10.1016/j.cellimm.2014.02.008

Urban, C. F., Ermert, D., Schmid, M., Abu-Abed, U., Goosmann, C., Nacken, W., et al. (2009). Neutrophil extracellular traps contain calprotectin, a cytosolic protein complex involved in host defense against Candida albicans. PLoS Pathog. 5:e1000639. doi: 10.1371/journal.ppat.1000639

Vandal, K., Rouleau, P., Boivin, A., Ryckman, C., Talbot, M., and Tessier, P. A. (2003). Blockade of S100A8 and S100A9 suppresses neutrophil migration in response to lipopolysaccharide. J. Immunol. 171, 2602-2609. doi: 10.4049/ jimmunol.171.5.2602

Veglia, F., Perego, M., and Gabrilovich, D. (2018). Myeloid-derived suppressor cells coming of age. Nat. Immunol. 19, 108-119. doi: 10.1038/s41590-017-0022-x

Voganatsi, A., Panyutich, A., Miyasaki, K. T., and Murthy, R. K. (2001). Mechanism of extracellular release of human neutrophil calprotectin complex. J. Leukoc. Biol. 70, 130-134.

Vogel, B., Claessen, B. E., Arnold, S. V., Chan, D., Cohen, D. J., Giannitsis, E., et al. (2019). ST-segment elevation myocardial infarction. Nat. Rev. Dis. Primers 5:39.

Vogl, T., Leukert, N., Barczyk, K., Strupat, K., and Roth, J. (2006). Biophysical characterization of S100A8 and S100A9 in the absence and presence of bivalent cations. Biochim Biophys Acta 1763, 1298-1306. doi: 10.1016/j.bbamcr.2006.08. 028

Vogl, T., Ludwig, S., Goebeler, M., Strey, A., Thorey, I. S., Reichelt, R., et al. (2004). MRP8 and MRP14 control microtubule reorganization during transendothelial migration of phagocytes. Blood 104, 4260-4268. doi: 10.1182/blood-2004-020446

Vogl, T., Stratis, A., Wixler, V., Voller, T., Thurainayagam, S., Jorch, S. K., et al. (2018). Autoinhibitory regulation of S100A8/S100A9 alarmin activity locally restricts sterile inflammation. J. Clin. Invest. 128, 1852-1866. doi: 10.1172/ jci89867

Vogl, T., Tenbrock, K., Ludwig, S., Leukert, N., Ehrhardt, C., van Zoelen, M. A., et al. (2007). Mrp8 and Mrp14 are endogenous activators of Toll-like receptor 4, promoting lethal, endotoxin-induced shock. Nat. Med. 13, 1042-1049. doi: $10.1038 / \mathrm{nm} 1638$

Volz, H. C., Laohachewin, D., Seidel, C., Lasitschka, F., Keilbach, K., Wienbrandt, A. R., et al. (2012). S100A8/A9 aggravates post-ischemic heart failure through activation of RAGE-dependent NF-kappaB signaling. Basic Res. Cardiol. 107:250.

Vora, A. N., Bonaca, M. P., Ruff, C. T., Jarolim, P., Murphy, S., Croce, K., et al. (2012). Diagnostic evaluation of the MRP-8/14 for the emergency assessment of chest pain. J. Thromb. Thrombolysis 34, 229-234. doi: 10.1007/s11239-0120705-y

Wache, C., Klein, M., Ostergaard, C., Angele, B., Hacker, H., Pfister, H. W., et al. (2015). Myeloid-related protein 14 promotes inflammation and injury in meningitis. J. Infect. Dis. 212, 247-257. doi: 10.1093/infdis/jiv028

Walters, A. M., Porter, G. A. Jr., and Brookes, P. S. (2012). Mitochondria as a drug target in ischemic heart disease and cardiomyopathy. Circ. Res. 111, 1222-1236. doi: 10.1161/circresaha.112.265660

Wan, E., Yeap, X. Y., Dehn, S., Terry, R., Novak, M., Zhang, S., et al. (2013). Enhanced efferocytosis of apoptotic cardiomyocytes through myeloidepithelial-reproductive tyrosine kinase links acute inflammation resolution to cardiac repair after infarction. Circ. Res. 113, 1004-1012. doi: 10.1161/ circresaha.113.301198

Wang, S., Song, R., Wang, Z., Jing, Z., Wang, S., and Ma, J. (2018). S100A8/A9 in Inflammation. Front. Immunol. 9:1298. doi: 10.3389/fimmu.2018.01298

Wang, Y., Fang, C., Gao, H., Bilodeau, M. L., Zhang, Z., Croce, K., et al. (2014). Platelet-derived S100 family member myeloid-related protein-14 regulates thrombosis. J. Clin. Invest. 124, 2160-2171. doi: 10.1172/jci70966

Wei, X., Wu, B., Zhao, J., Zeng, Z., Xuan, W., Cao, S., et al. (2015). Myocardial Hypertrophic Preconditioning Attenuates Cardiomyocyte Hypertrophy and Slows Progression to Heart Failure Through Upregulation of S100A8/A9. Circulation 131, 1506-1517. doi: 10.1161/circulationaha.114.013789

Wu, Y., Li, Y., Zhang, C., Xi, A., Wang, Y., Cui, W., et al. (2014). S100a8/a9 released by $\mathrm{CD} 11 \mathrm{~b}+\mathrm{Gr} 1+$ neutrophils activates cardiac fibroblasts to initiate angiotensin II-Induced cardiac inflammation and injury. Hypertension 63, 1241-1250. doi: 10.1161/hypertensionaha.113.02843

Yao, D., and Brownlee, M. (2010). Hyperglycemia-induced reactive oxygen species increase expression of the receptor for advanced glycation end products (RAGE) and RAGE ligands. Diabetes 59, 249-255. doi: 10.2337/db09-0801

Zimmer, D. B., Eubanks, J. O., Ramakrishnan, D., and Criscitiello, M. F. (2013). Evolution of the S100 family of calcium sensor proteins. Cell Calcium 53, 170-179. doi: 10.1016/j.ceca.2012.11.006

Zou, X., Sorenson, B. S., Ross, K. F., and Herzberg, M. C. (2013). Augmentation of epithelial resistance to invading bacteria by using mRNA transfections. Infect. Immun. 81, 3975-3983. doi: 10.1128/iai.00539-13

Conflict of Interest: The authors declare that the research was conducted in the absence of any commercial or financial relationships that could be construed as a potential conflict of interest.

Copyright (c) 2020 Cai, Xie, Hu, Yao, Zhao, Wu and Tang. This is an open-access article distributed under the terms of the Creative Commons Attribution License (CC BY). The use, distribution or reproduction in other forums is permitted, provided the original author(s) and the copyright owner(s) are credited and that the original publication in this journal is cited, in accordance with accepted academic practice. No use, distribution or reproduction is permitted which does not comply with these terms. 